\title{
Carbohydrate-based activated carbon with high surface acidity and basicity for nickel removal from synthetic wastewater
}

\author{
Hai Liu, ${ }^{\text {ac }}$ Jian Zhang, ${ }^{* a}$ Huu Hao Ngo, ${ }^{b}$ Wenshan Guo, ${ }^{b}$ Haiming Wu, ${ }^{\mathrm{d}}$ Cheng Cheng, ${ }^{\mathrm{a}}$ Zizhang Guo \\ and Chenglu Zhang ${ }^{\mathrm{a}}$

\begin{abstract}
a Shandong Key Laboratory of Water Pollution Control and Resource Reuse, School of Environmental Science and Engineering, Shandong University, Jinan 250100, China. E-mail: zhangjian00@ sdu.edu.cn; shandaliuhai @ berkeley.edu; Fax: +86 53188364513 ; Tel: +8653188363015

${ }^{\mathrm{b}}$ School of Civil and Environmental Engineering, University of Technology Sydney, Broadway, NSW 2007, Australia

'Department of Chemical and Biomolecular Engineering, University of California, Berkeley, California 94720, USA

d College of Resources and Environment, Northwest A \& F University, Yangling, Shaanxi 712100, China
\end{abstract}

The feasibility of preparing activated carbon (AC-CHs) from carbohydrates (glucose, sucrose and starch) with phosphoric acid activation was evaluated by comparing its physicochemical properties and $\mathrm{Ni}$ (II) adsorption performance with a reference activated carbon (AC-PA) derived from Phragmites australis. The textural and chemical properties of the prepared activated carbon were characterized by $\mathrm{N}_{2}$ adsorption/desorption isotherms, SEM, Boehm's titration and XPS. Although AC-CHs had much lower surface area (less than $\left.700 \mathrm{~m}^{2} \mathrm{~g}^{-1}\right)$ than AC-PA $\left(1057 \mathrm{~m}^{2} \mathrm{~g}^{-1}\right)$, they exhibited 45-70\% larger Ni(II) adsorption capacity which could be mainly attributed to their 50-75\% higher contents of total acidic and basic groups. The comparison of XPS analyses for starch-based activated carbon before and after $\mathrm{Ni}$ (II) adsorption indicated that $\mathrm{Ni}$ (II) cation combined with the oxygencontaining groups and basic groups (delocalized $\pi$-electrons) through the mechanisms of proton exchange, electrostatic attraction, and surface complexation. Kinetic results suggested that chemical reaction was the main rate-controlling step, and a very quick $\mathrm{Ni}$ (II) adsorption performance of ACCHs was presented with $\sim 95 \%$ of maximum adsorption within $30 \mathrm{~min}$. Both adsorption capacity and rate of the activated carbon depended on the surface chemistry as revealed by batch adsorption experiments and XPS analyses. This study demonstrated that AC-CHs could be promising materials for $\mathrm{Ni}(\mathrm{II})$ pollution minimization.

\section{Introduction}

Nickel contamination has been regarded as a universal environmental problem, and excessive nickel compounds have been detected frequently in sediment samples from different countries during the last 20 years. ${ }^{1-4}$ As an integral metal to world economic development, nickel is extensively used in many specific and recognizable products, such as nickel steels, super-alloys, electroplating and rechargeable batteries. Although nickel is ubiquitous in the ecosystem and is an essential micronutrient for living organisms, nickel with high concentration derived from sewage discharge or bioaccumulation is known as an embryotoxin, a teratogen and possible carcinogen to humans and animals. ${ }^{7,8}$ Hence, nickel compounds have been considered as a priority pollutant by institutions around the world (e.g. EPA U.S. and WHO/IARC ${ }^{10}$ ). Moreover, there is an increasing demand for developing more effective techniques to remove such pollutant from wastewater. Adsorption onto functional porous carbon materials, especially activated carbon, is very simple and effective way for eliminating undesirable metal ions from contaminated water.

For a given adsorbate, both porous texture and surface chemistry of activated carbon have distinct effects on its adsorption capacity and rate toward. ${ }^{14,15}$ Pore effect (micropore filling/size exclusion) might be involved in adsorption onto porous carbon materials depending on the geometry of adsorbate and pores of activated carbon. Since Ni(II) has low ionic diameter $(0.138 \mathrm{~nm})$ and hydrated 
ionic radius $(0.425 \mathrm{~nm}),{ }^{16} \mathrm{Ni}(\mathrm{II})$ species can be withheld by some narrow micropores. The welldeveloped structure of activated carbon can also provide a large contact area for the interfacial interactions. As the most conventional hetero-complexes, oxygen containing groups can delocalize electrons of the associated graphene sheets, and determine the acidic or basic characters of the activated carbon surface. In particular, the (deprotonated) acidic oxygenated groups such as carboxylic, lactonic and phenolic groups are able to bind metal cations by electrostatic attraction, ion exchange or complexation. ${ }^{18,19}$ Additionally, the basic groups (delocalized lone-pair $\pi$ electrons) can form electron donor-acceptor complexes with metal ions via proton exchange $\left(-\mathrm{C}^{2}-\mathrm{H}_{3} \mathrm{O}^{+}\right)$or coordination $(-\mathrm{C} \pi)^{20}$

The physiochemical characteristics of activated carbon are mainly determined by the carbon precursor as well as the activation method and condition. It has been well-demonstrated that introduction of oxygen functionalities onto carbon materials is a promising strategy to enhance its adsorption capacity of heavy metal ions. ${ }^{21-24}$ After activation in either gas or liquid phase with oxidants/reductants, the post-oxidation/reduction treatments of commercial activated carbon or carbon materials have been successfully applied to increase the surface oxygenated groups, eventually promoting adsorption ability. These modification techniques not only involve timeconsuming and additional processes, but also lead to a drastic reduction of the total basic groups, such as the chemical treatments with $\mathrm{H}_{2} \mathrm{O}_{2},{ }^{25} \mathrm{HNO}_{3},{ }^{26}\left(\mathrm{NH}_{4}\right)_{2} \mathrm{~S}_{2} \mathrm{O}_{8},{ }^{27}$ and $\mathrm{O}_{3}{ }^{28}$ Thus, considering the huge influence of surface chemistry on the performance of carbon materials, it is interesting to explore a better/new way to produce activated carbon with both high surface acidity and basicity.

Dissolved organic compounds, especially carbohydrates (such as glucose, sucrose and starch), are especially used as carbon precursor to prepare hydrochar through hydrothermal carbonization. The produced hydrochar possesses less functional groups and low pore volume, which limits its application potential. $^{29,30}$ However, limited literature has been reported on synthesis of functional carbon materials directly from carbohydrates by chemical activation. Based on our previous studies, the feasibility of production of activated carbon by activation with organophosphorus compounds has been confirmed. ${ }^{18,31}$ The produced activated carbon showed much higher acidic and basic groups contents than activated carbon derived from conventional phosphoric acid activation due to the oxidation of the radicals decomposed from organophosphates. It is well known that carbohydrates are polyhydroxy aldehydes and ketones with many alcoholic hydroxyl groups. Phosphoric acid can form phosphate or polyphosphate esters with carbohydrates at high temperature, and the formed phosphate eaters are extremely unstable and easily decompose into phosphorus oxide and radicals. Therefore, there is a huge possibility to prepare highly functional carbon materials from carbohydrates by phosphoric acid activation.

The aims of this work was to investigate the feasibility of synthesizing activated carbon (AC-CHs) by using carbohydrates (glucose, sucrose and starch) as carbon precursors with phosphoric acid activation with high surface acidity and basicity, and performance of Ni(II) removal. The specific objectives included (1) evaluating the physiochemical and adsorption properties of the AC-CHs in terms of the pore structure, surface chemistry and $\mathrm{Ni}$ (II) removal by comparing with the activated carbon made from a lignocellulose material; and (2) discussing the mechanisms governing Ni(II) adsorption onto the activated carbon based on batch experiments and XPS analysis.

\section{Materials and methods}

\subsection{Materials}

All the chemical reagents (analytical grade) were used as purchased. Three types of carbohydrates, 
namely glucose, sucrose and starch, were chosen as carbon precursors. Utilization of various hydrophyte residues as carbon precursors for preparing activated carbons with well-developed structure and favorable surface chemistry via phosphoric acid activation has been well demonstrated by our previous reports. ${ }^{18,31,32}$ For comparison purpose, Phragmites australis (elemental compositions: $\mathrm{C}, 45.1 \%$; O, 48.3\%; and $\mathrm{H}, 5.9 \%$ ) with particle size of approx. 0.45-1.0 mm was used for activated carbon preparation. $\mathrm{Ni}^{2+}$ solution was prepared by dissolving a weighed quantity of analytical grade $\mathrm{NiCl}_{2}$ in distilled water.

\subsection{Preparation of activated carbons}

Carbon precursors were mixed with $\mathrm{H}_{3} \mathrm{PO}_{4}(85 \mathrm{wt} \%)$ solution at a impregnation ratio of 2.0 (g $\mathrm{H}_{3} \mathrm{PO}_{4} /$ precursor $)$. After soaking at room temperature $\left(25^{\circ} \mathrm{C}\right)$ for $12 \mathrm{~h}$, the samples were heated to $450{ }^{\circ} \mathrm{C}$ and maintained for $1 \mathrm{~h}$ in a tubular furnace with a heating rate of $10^{\circ} \mathrm{C} \mathrm{min}{ }^{-1}$ under $\mathrm{N}_{2}$ atmosphere $\left(150 \mathrm{~cm}^{3} \mathrm{~min}^{-1}\right)$. The activated samples were then washed with distilled water after cooling to room temperature to obtain steady $\mathrm{pH}$ and negative phosphate analysis in the filtrate. Afterwards, the resulting activated carbons were dried at $105^{\circ} \mathrm{C}$ for $12 \mathrm{~h}$, and then grounded and sieved to a particle size of 120-160 mesh with standard sieves (Model F200). Activated carbons derived from glucose, sucrose, starch and Phragmites australis were denoted as AC-Glu, AC-Suc, AC-Sta, and AC-PA, respectively.

\subsection{Characterization methods}

The main physical and chemical properties of activated carbon were characterized by $\mathrm{N}_{2}$ absorption and desorption, scanning electron microscope (SEM), Boehm's titration, point of zero charge analysis and X-ray photoelectron spectra (XPS). After degasing at $250^{\circ} \mathrm{C}$ for $6 \mathrm{~h}$, the pore texture parameters of activated carbon were determined from $\mathrm{N}_{2}$ adsorption and desorption isotherms measured at $77 \mathrm{~K}$ with a surface area analyzer (Quantachrome Corporation, USA). Boehm's titration method ${ }^{33}$ was used to quantify the amounts of acidic and basic functional groups on surface of activated carbon. The determination of $\mathrm{pH}_{\mathrm{pzc}}$ (point of zero charge) was carried out following a batch method proposed in the literature. ${ }^{34}$ The surface binding state and elemental speciation of the activated carbons (AC-Sta before and after $\mathrm{Ni}$ (II) adsorption) were analyzed with an X-ray photoelectron spectrometer (XPS) (Perkin-Elmer PHI 550 ESCA/SAM). All the spectra were corrected by C 1s $(284.6 \mathrm{eV})$ band.

\subsection{Nickel adsorption}

Batch adsorption experiments were performed to investigate the effects of contact time, initial $\mathrm{Ni}(\mathrm{II})$ concentration $\left(10-60 \mathrm{mg} \mathrm{L}^{-1}\right)$, solution $\mathrm{pH}(2.0-7.0)$, and ionic strength $(0-500 \mathrm{mM} \mathrm{NaCl})$ on adsorption performance. They were carried out by adding $30 \mathrm{mg}$ carbon into $50 \mathrm{~mL} \mathrm{Ni(II)}$ solution and shaken at $200 \mathrm{rpm}$ in a temperature controlled shaking water bath for $24 \mathrm{~h}$. In most experiments, solution $\mathrm{pH}$ was adjusted to a certain value (6.0) by adding $0.1 \mathrm{~mol} \mathrm{~L}^{-1} \mathrm{NaOH}$ or $\mathrm{HCl}$ and measured with a pH-meter (Model pHS-3C, Shanghai). After shaking at $25^{\circ} \mathrm{C}$ for $24 \mathrm{~h}$, the solid and liquid phases were separated using $0.45 \mathrm{~mm}$ membrane filter. $\mathrm{Ni}$ (II) concentration in the filtrate was determined using an atomic absorption spectrophotometer (180-80, Hitachi, Japan). Ni(II) adsorbed onto carbon, $\mathrm{Q}_{\mathrm{e}}\left(\mathrm{mg} \mathrm{g}^{-1}\right)$, was calculated by a mass balance: $\mathrm{Q}_{\mathrm{e}}=\left(\mathrm{C}_{0}-\mathrm{C}_{\mathrm{e}}\right) \mathrm{V} / \mathrm{M}$, where $\mathrm{C}_{0}$ and $\mathrm{C}_{\mathrm{e}}$ are the initial and equilibrium concentrations of the heavy metal ions in aqueous solution $\left(\mathrm{mg} \mathrm{L}^{-1}\right)$, respectively; $\mathrm{V}$ is the volume (L) of $\mathrm{Ni}(\mathrm{II})$ solution, and $\mathrm{M}$ is the mass of carbon used ( $\mathrm{g}$ ). All batch adsorption experiments were performed in triplicate and the results were averaged. 


\section{Results and discussion}

\subsection{Textural characteristics of adsorbents}

$\mathrm{N}_{2}$ adsorption and desorption isotherms and pore size distributions for activated carbons are depicted in Fig. 1. Mesoporous structure for each activated carbon was indicated by the presence of hysteresis for each isotherm at $\mathrm{P} / \mathrm{P}_{0}$ above 0.4 (Fig. 1a). The results also can be confirmed by pore size distributions that the carbon had some pores with pore width between 2 and $16 \mathrm{~nm}$ (Fig. 1b). AC-PA exhibited a much wider pore size distribution (pore width: $16 \mathrm{~nm}$ ) than other activated carbon (below $10 \mathrm{~nm}$ ). The textural parameters of the carbon materials are shown in Table 1. AC-PA possessed the largest surface area, $V_{\text {mic }}$ and $V_{\text {ext }}$ than the carbon (AC-CHs) derived from carbohydrates, which mainly consisted of mesopores with a mesoporosity of about $90 \%\left(\mathrm{~V}_{\text {ext }} / \mathrm{V}_{\text {tot }}\right)$. For AC-CHs, AC-Sta was nearly nonporous with the lowest surface area $\left(12.1 \mathrm{~m}^{2} \mathrm{~g}^{-1}\right)$ and pore volume $\left(0.008 \mathrm{~cm}^{3} \mathrm{~g}^{-1}\right)$, whereas AC-Glu and AC-Suc exhibited micro-mesoporous structure and higher pore volume.

The surface morphology of carbon was also characterized using SEM images (Fig. 2a). The highest surface area of AC-PA could be further evident from these SEM images as AC-CHs showed less porous structure than AC-PA. Some broken bubbles, fragments or particles were observed on the surface of AC-CHs, reflecting the formation of highly cross-linked structure, decomposition of phosphates, and release of radical species, as reported in our previous papers. ${ }^{32,35}$ These reactions eventually resulted in their porous structure and surface chemistry (Section 3.2).

\subsection{Chemical characteristics of adsorbents}

As shown in Fig. 2b, the XPS survey spectra of the carbon revealed that the surface elemental compositions consisted mainly of carbon and oxygen, representing that these acidic and basic groups were derived from the combination of carbon and/ or oxygen complexes. The stronger oxygen peaks and the higher $\mathrm{O} / \mathrm{C} \%$ of $\mathrm{AC}-\mathrm{CHs}$ indicated that they possessed much more oxygen-containing functional groups than AC-PA, which were consistent with the results of Boehm's titration (see Table 1). As AC-CHs were porous (except AC-Sta), a large portion of the oxygen-containing groups was located internally of the pores. However, XPS could only detect the surface elemental compositions. Thus, although AC-Glu presented the highest surface acidity, it showed a relatively low O/C\%. It can be also recognized that the order of $\mathrm{O} / \mathrm{C} \%$ of each carbon was in agreement with its density of acidity based on the surface area (see Table 1).
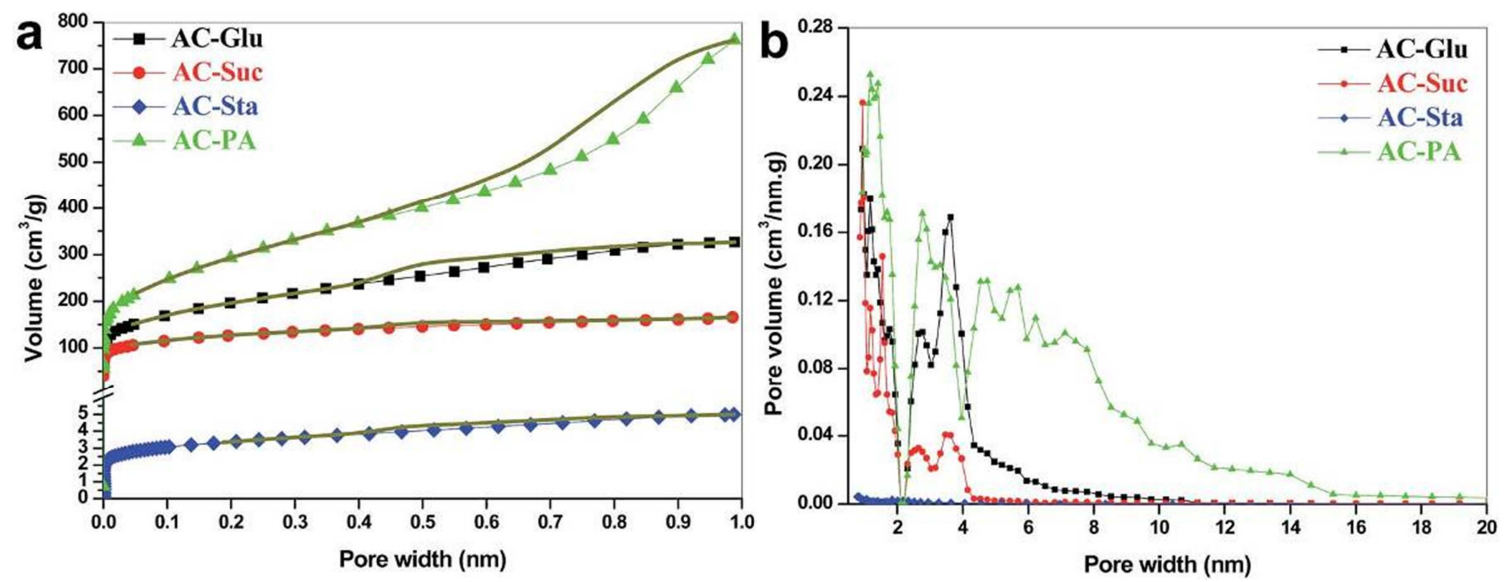

Fig. $1 \mathrm{~N}_{2}$ adsorption and desorption isotherms (a) and pore size distributions (b) of the carbons samples. 


\begin{tabular}{|c|c|c|c|c|}
\hline Activated carbon & AC-Glu & AC-Suc & AC-Sta & AC-PA \\
\hline$S_{\mathrm{BET}}{ }^{a}\left(\mathrm{~m}^{2} \mathrm{~g}^{-1}\right)$ & 698 & 460 & 12.1 & 1057 \\
\hline$V_{\text {mic }}{ }^{b}\left(\mathrm{~cm}^{3} \mathrm{~g}^{-1}\right)$ & 0.132 & 0.123 & 0.003 & 0.151 \\
\hline$V_{\text {mic }} / V_{\text {tot }}(\%)$ & 26.2 & 48.8 & 37.5 & 13.5 \\
\hline$V_{\text {ext }}\left(\mathrm{cm}^{3} \mathrm{~g}^{-1}\right)$ & 0.372 & 0.129 & 0.005 & 0.966 \\
\hline$V_{\text {tot }}^{c}\left(\mathrm{~cm}^{3} \mathrm{~g}^{-1}\right)$ & 0.504 & 0.252 & 0.008 & 1.117 \\
\hline Carboxylic groups $^{d}\left(\mathrm{mmol} \mathrm{g}^{-1}\right)$ & 1.214 & 1.062 & 1.117 & 0.836 \\
\hline Lactonic groups $^{d}\left(\mathrm{mmol} \mathrm{g}^{-1}\right)$ & 0.908 & 0.764 & 0.777 & 0.386 \\
\hline Phenolic groups $^{d}\left(\mathrm{mmol} \mathrm{g}^{-1}\right)$ & 1.166 & 1.045 & 1.071 & 0.701 \\
\hline Total acidity $^{d}\left(\mathrm{mmol} \mathrm{g}^{-1}\right)$ & 3.288 & 2.871 & 2.965 & 1.923 \\
\hline Density of acidity $\left(\times 10^{-3} \mathrm{mmol} \mathrm{m}^{-2}\right)$ & 4.71 & 6.22 & 245 & 1.83 \\
\hline Total basicity $^{d}\left(\mathrm{mmol} \mathrm{g}^{-1}\right)$ & 2.016 & 1.873 & 1.943 & 1.113 \\
\hline Total groups $\left(\mathrm{mmol} \mathrm{g}^{-1}\right)$ & 5.304 & 4.744 & 4.908 & 3.036 \\
\hline $\mathrm{pHpzc}^{e}$ & 6.71 & 6.15 & 6.12 & 5.87 \\
\hline $\mathrm{O} / \mathrm{C} \%$ (weight ratio) $^{f}$ & 102.2 & 116.4 & 145.3 & 84.9 \\
\hline $\mathrm{p}^{g_{\%}} \%$ & BDL & BDL & BDL & BDL \\
\hline
\end{tabular}

${ }^{a}$ BET surface area $\left(\mathrm{S}_{\mathrm{BET}}\right)$ was determined by using the Brunauer- Emmett-Teller $(\mathrm{BET})$ theory. ${ }^{\mathrm{b}}$ Micropore surface area $\left(\mathrm{S}_{\text {mic }}\right)$ and micropore volume $\left(\mathrm{V}_{\text {mic }}\right)$ were evaluated by the t-plot method. ${ }^{\mathrm{c}}$ Total pore volume $\left(\mathrm{V}_{\text {tot }}\right)$ was determined from the amount of $\mathrm{N}_{2}$ adsorbed at a $\mathrm{P} / \mathrm{P}_{0}$ around 0.95 . ${ }^{\mathrm{d}}$ Boehm's titration. ${ }^{\mathrm{e}} \mathrm{pH}_{\mathrm{pzc}}$ : point of zero charge. ${ }^{\mathrm{f}}$ Determined by X-ray photoelectron spectroscopy (XPS). ${ }^{\mathrm{g}}$ Below detectable level.

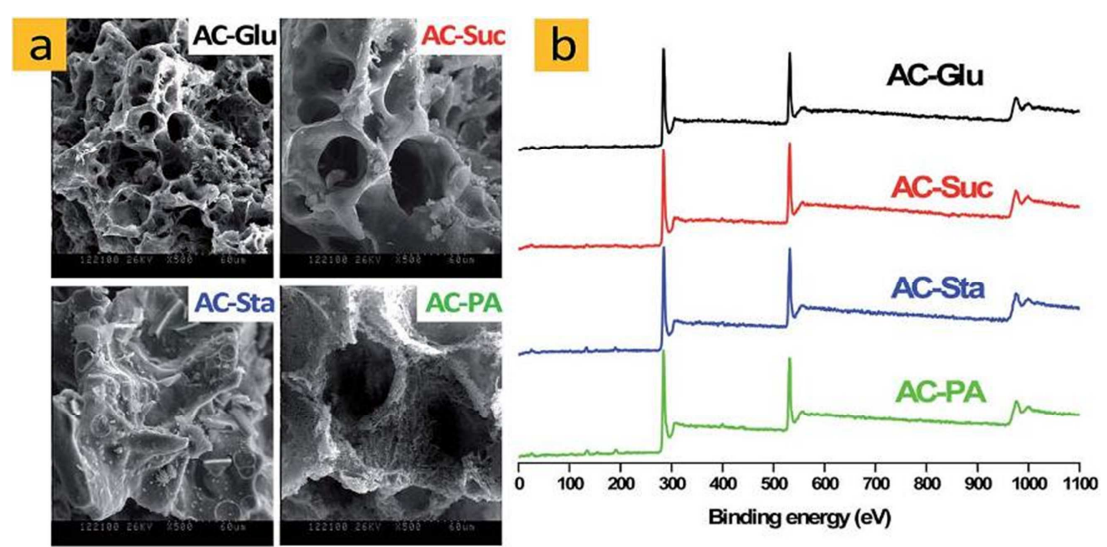

Fig. 2 Surface morphology (a) and XPS survey spectra (b) of the carbons samples.

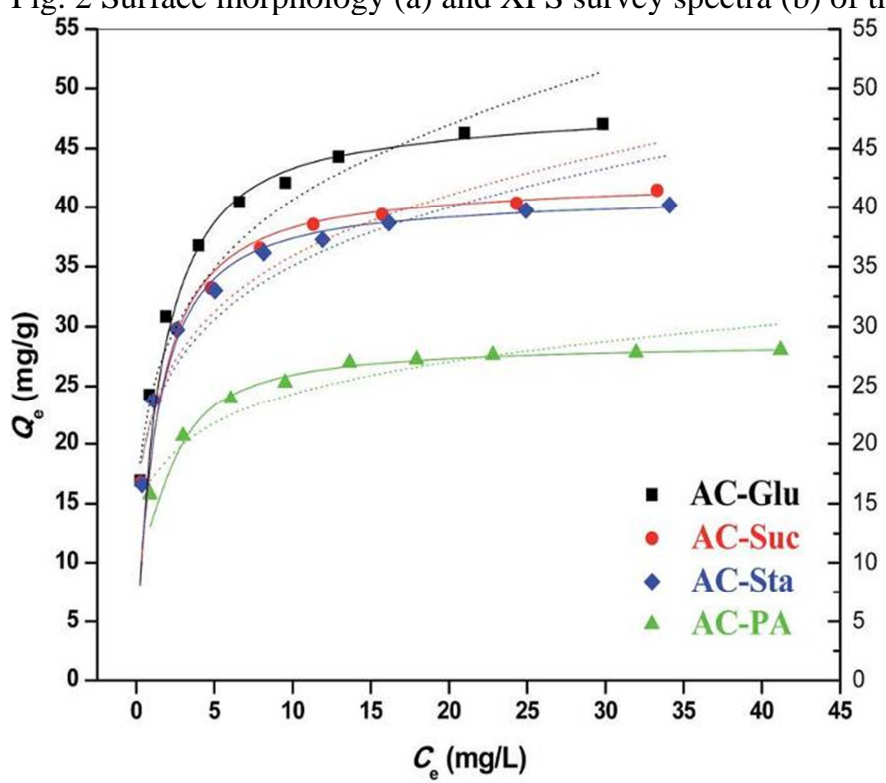

Fig.3 Adsorption isotherms of nickel on unit mass basis for the carbons samples. Solid lines represent the Langmuir isotherms and dashlines represent the Freundlich isotherms (dosage $=0.6 \mathrm{gL}^{-1}$, temperature $=25 \pm 2{ }^{\circ} \mathrm{C}$, initial $\mathrm{pH}=6.00$ \pm 2 , time $=24 \mathrm{~h}$ ). 
Generally, carboxyl, phenolic hydroxyl and lactonic groups are acidic, while, the basicity of activated carbon derives primarily from delocalized $\pi$-electrons of graphene structure with small contribution from oxygen containing surface functionalities (such as pyrene, chromene and quinone). 36,37 The main surface chemical properties of the carbon are listed in Table 1. Obvious differences existed between the amounts of acidic and basic functional groups of the carbon, confirming the observed $\mathrm{pH}_{\mathrm{pzc}}$ existed within acidic range. AC-CHs contained notably larger amounts of acidic and basic groups than AC-PA. The amount of acidic groups on the carbon followed an order of carboxyl > phenol > lactone.

\subsection{Adsorption isotherms}

Adsorption isotherms of $\mathrm{Ni}(\mathrm{II})$ on carbon are shown in Fig. 3. The adsorption data were fitted to the Langmuir $\left(Q_{e}=Q_{m} K_{L} C_{e} /\left(1+K_{L} C_{e}\right)\right)$ and Freundlich models $\left(Q_{e}=K_{F} C_{e}{ }_{-1}^{1 / n}\right)$, where $Q_{1-1 / n}\left(m_{-1} g^{-1}\right)$ is the monolayer adsorption capacity, $\mathrm{K}_{\mathrm{L}}\left(\mathrm{L} \mathrm{mg}^{-1}\right)$ is the Langmuir constant, $\mathrm{K}_{\mathrm{F}}\left(\mathrm{mg}^{1-1 / \mathrm{n}} \mathrm{g}^{-1}\right)$ is the Freundlich affinity coefficient, and $\mathrm{n}$ is the adsorption intensity.

Table 2 Langmuir and Freundlich isotherm constants for the nickel adsorption onto the carbons ${ }^{a}$

\begin{tabular}{|c|c|c|c|c|c|}
\hline \multirow[b]{2}{*}{ Isotherm models } & \multirow[b]{2}{*}{ Constants } & \multicolumn{4}{|l|}{ Carbons } \\
\hline & & AC-Glu & AC-Suc & AC-Sta & AC-PA \\
\hline \multirow[t]{8}{*}{ Langmuir } & $K_{\mathrm{L}}\left(\mathrm{L} \mathrm{mg}^{-1}\right)$ & 0.8516 & 0.9752 & 1.001 & 0.9528 \\
\hline & $Q_{\mathrm{m}}\left(\mathrm{mg} \mathrm{g}^{-1}\right)$ & 48.5 & 42.4 & 41.1 & 28.7 \\
\hline & $Q_{\mathrm{m}} / S_{\mathrm{BET}}\left(\mathrm{mg} \mathrm{m}^{-2}\right)$ & 6.92 & 9.22 & 339 & 2.72 \\
\hline & $Q_{\mathrm{m}} / V_{\text {mic }}\left(\mathrm{mg} \mathrm{cm}^{-3}\right)$ & 3.67 & 3.45 & 137 & 1.90 \\
\hline & $Q_{\mathrm{m}} /$ acidity $\left(\mathrm{mg} \mathrm{mmol}^{-\mathbf{1}}\right)$ & 14.87 & 14.77 & 13.86 & 14.92 \\
\hline & $Q_{\mathrm{m}} /$ total groups $\left(\mathrm{mg} \mathrm{mmol}^{-1}\right)$ & 9.14 & 8.94 & 8.37 & 9.45 \\
\hline & $R^{2}$ & 0.9998 & 0.9981 & 0.9994 & 0.9996 \\
\hline & APE (\%) & 1.15 & 2.76 & 2.15 & 2.09 \\
\hline \multirow{4}{*}{ Freundlich } & $K_{\mathrm{F}}\left(\mathrm{mg} \mathrm{g}^{-1}\left(\mathrm{~L} \mathrm{mg}^{-1}\right)^{1 / n}\right)$ & 24.96 & 23.03 & 22.71 & 17.24 \\
\hline & $1 / n$ & 0.2128 & 0.1941 & 0.1903 & 0.1509 \\
\hline & $R^{2}$ & 0.9299 & 0.9731 & 0.9497 & 0.9346 \\
\hline & APE $(\%)$ & 4.22 & 4.53 & 5.58 & 6.19 \\
\hline
\end{tabular}

The relative parameters calculated from the Langmuir and Freundlich isotherm models are listed in Table 2. The adsorption isotherms for the carbon along with the non-linear of experimental data are presented in Fig. 3. As shown in the Table 2 and Fig. 3, the Langmuir model fitted the data better than the Freundlich model with higher $\mathrm{R}^{2}$ and lower APE, implying that $\mathrm{Ni}$ (II) adsorption on activated carbon was a monolayer adsorption due to the strong adsorption interactions. The values of exponent $1 / \mathrm{n}$ were in the range of $0-1$, which indicated a favorable $\mathrm{Ni}$ (II) adsorption.

The $\mathrm{Q}_{\mathrm{m}}$ calculated from the Langmuir isotherm has widely been used to quantify and compare the adsorption capacities of different adsorbents, assisting in optimization design of adsorption system. The $\mathrm{Q}_{\mathrm{m}}$ values of AC-CHs were much higher that of AC-PA, meaning that these carbohydrates could be used as excellent precursor for preparing activated carbon with relatively high adsorption capacity of $\mathrm{Ni}(\mathrm{II})$. With comparison of the $\mathrm{Q}_{\mathrm{m}}$ values based on the surface area, micropore volume, and surface functionality (Table 2), no apparent correlation could be generalized based on the surface area and porosity, whereas the $\mathrm{Q}_{\mathrm{m}} /$ total groups $\left(\mathrm{mg} \mathrm{mmol}^{-1}\right.$ ) could roughly correspond to surface acidities and total groups of the carbon, implying that surface chemistry was the dominated factor influencing $\mathrm{Ni}(\mathrm{II})$ adsorption.

As shown in Table 2, the nonporous carbon (AC-Sta) exhibited dramatically higher $\mathrm{Q}_{\mathrm{m}} / \mathrm{S}_{\mathrm{BET}}$ and 
$\mathrm{Q}_{\mathrm{m}} / \mathrm{V}_{\text {mic }}$ than other porous carbon materials (AC-Glu, AC-Suc and AC-PA, surface area above 450 $\mathrm{m}^{2} \mathrm{~g}^{-1}$ ), but slightly lower $\mathrm{Q}_{\mathrm{m}}$ /acidity $\left(13.86 \mathrm{mg} \mathrm{mmol}^{-1}\right.$ ) than AC-Glu, AC-Suc and AC-PA (14.71$\left.14.92 \mathrm{mg} \mathrm{mmol}^{-1}\right)$. Micropore-filling effect was expected to occur when pore size of carbon and diameter of (hydrated) nickel cation were similar. Furthermore, AC-Suc had much larger $\mathrm{S}_{\mathrm{BET}}$ and slightly less acidic groups than AC-Sta, and its $\mathrm{Q}_{\mathrm{m}}\left(42.4 \mathrm{mg} \mathrm{g}^{-1}\right)$ was slightly larger than that of ACSta (41.1 $\mathrm{mg} \mathrm{g}^{-1}$ ). Therefore, it can be concluded that micropore-filling contributed to $\mathrm{Ni}$ (II) adsorption. However, the minor differences in $\mathrm{Q}_{\mathrm{m}}$ /acidity values elucidated that such pore effect was weak and even could be negligible in comparison to the effect of surface chemistry.

Generally, the isotherm-fitting cannot provide any strong evidence for the actual adsorption mechanisms. The differences in Ni(II) adsorption capacity was principally due to the amount of surface groups of carbon. Based on the literature ${ }^{38,39}$ and our previous findings, ${ }^{18,21}$ chemical adsorption mechanisms of metal cation on activated carbon mainly include electrostatic attraction, ion exchange, and complexation. Thus, to further identify these adsorptive interactions between $\mathrm{Ni}(\mathrm{II})$ and the carbon surface, the influence of solution $\mathrm{pH}$ and ionic strength on $\mathrm{Ni}$ (II) adsorption and the XPS analysis of AC-Sta (nonporous carbon materials) before and after Ni(II) adsorption were further investigated.

\subsection{Effect of $\mathbf{p H}$}

The species of $\mathrm{Ni}(\mathrm{II})$ in aqueous solution are strongly dependent on solution $\mathrm{pH}$. Since $\mathrm{Ni}(\mathrm{OH})_{2}$ has a low solubility $\left(\mathrm{K}_{\mathrm{sp}}=2.0 \times 10^{-15}\right)$, it can be formed easily at weak alkaline conditions. The $\mathrm{pH}$ for precipitation of $\mathrm{Ni}^{2+}$ solution at initial concentration ranging from 10 to $50 \mathrm{mg} \mathrm{L}^{-1}$ is $8.53-8.15$. Thus, during the batch experiments, solution pHs were controlled in the range of 2.0-7.0 to avoid precipitation. Fig. 4a shows Ni(II) adsorption was strongly affected by solution $\mathrm{pH}$. The adsorption of $\mathrm{Ni}$ (II) increased sharply as the $\mathrm{pH}$ increased from 2 to 4, then grew slowly at $\mathrm{pH} 4-7$. The predominant species of $\mathrm{Ni}$ (II) in aqueous solution under $\mathrm{pH}$ blow 7.0 were $\mathrm{Ni}^{2+}$ cation with a very small part of $\mathrm{Ni}(\mathrm{OH})^{+}$. ${ }^{41}$ Thus, $\mathrm{Ni}(\mathrm{II})$ adsorption was mainly governed by the changes of $\mathrm{H}^{+}$ concentration and surface charges of the carbon.

At lower initial $\mathrm{pHs}$, the higher concentration of $\mathrm{H}^{+}$ions effectively enhanced cations competition with $\mathrm{Ni}^{2+}$ for adsorption sites. Meanwhile, the delocalized $\pi$ electrons $(-\mathrm{C} \pi)$ of graphene layers in activated carbon formed electron donor- acceptor complexes with $\mathrm{H}_{3} \mathrm{O}^{+}$molecules, ${ }^{20,42}$ leading to the stronger electrostatic repulsion between carbon surface and $\mathrm{Ni}^{2+}$ cations. At higher $\mathrm{pHs}$, the competition between $\mathrm{H}^{+}$and $\mathrm{Ni}^{2+}$ became weak, and the surface of carbon gradually became negatively charged due to deprotonation of $-\mathrm{C} \pi-\mathrm{H}_{3} \mathrm{O}^{+}$and dissociation of acidic groups. Thus, more $\mathrm{Ni}$ (II) cations passing through the carbon surface could be eventually adsorbed by enhanced electrostatic attraction. 

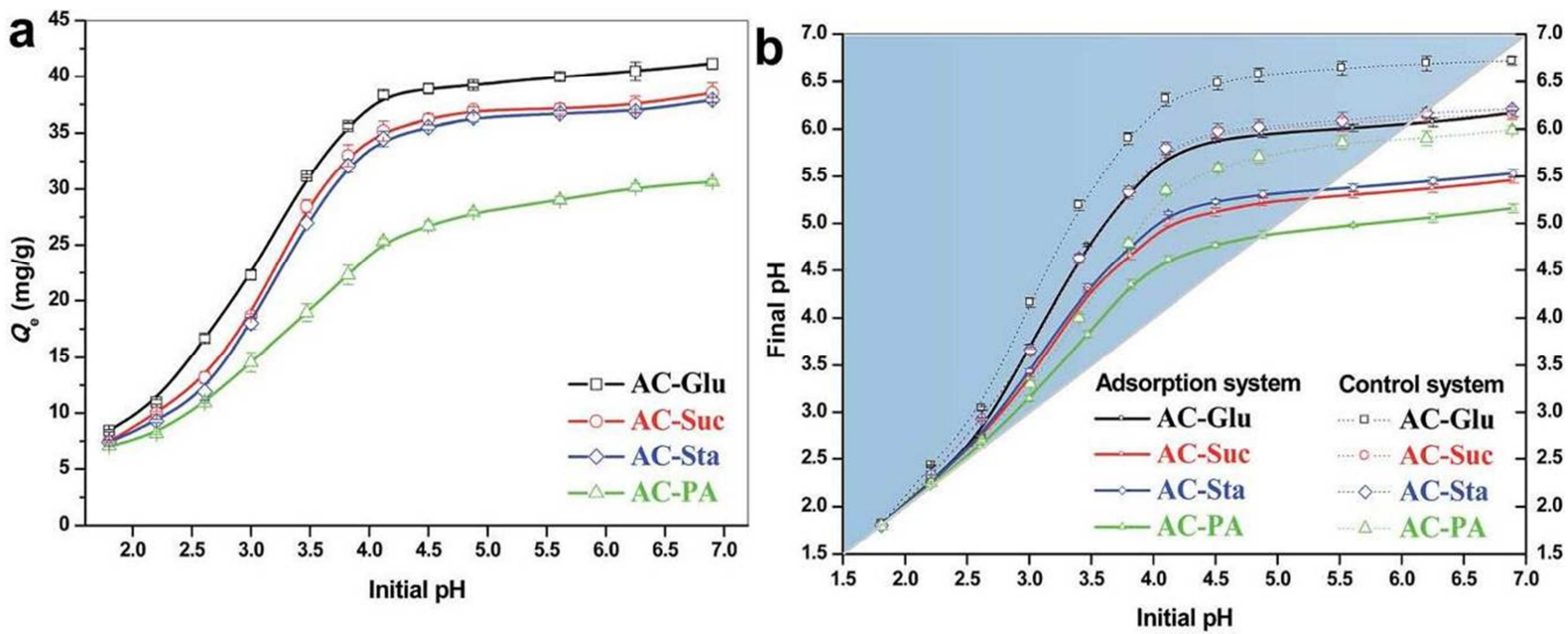

Fig.4 Effect of pH on nickel adsorption by the carbons samples (a). The effect of nickel adsorption on solution $\mathrm{pH}$ (b): adsorption system and control system are the batch experiments by adding carbon sample to nickel solution or distilled water with different initial $\mathrm{pH}\left(\right.$ dosage $=0.6 \mathrm{gL}^{-1}$, temperature $=25 \pm 2{ }^{\circ} \mathrm{C}$, initial $\mathrm{pH}=6.00 \pm 2$, time $\left.=24 \mathrm{~h}\right)$.

The final $\mathrm{pH}$ of the adsorption system and the control system were examined for evaluating the ion exchange mechanisms (Fig. 4b). At low pH, the basic groups of activated carbon neutralize excessive $\mathrm{H}^{+}$ions, while at high $\mathrm{pH}$ the acidic groups neutralize excessive $\mathrm{OH}^{-}$ions. The tested carbon possessed a certain acidity and basicity, and thus resulted in an increase/a decrease of the final $\mathrm{pH}$ at initial solution $\mathrm{pH}$ below/above $\mathrm{pH}_{\mathrm{pzc}} \mathrm{S}$ of the carbons for the control systems (Fig. 4b). It was obvious that final $\mathrm{pH}$ of each adsorption system were much lower than that of control system, indicating that $\mathrm{Ni}(\mathrm{II})$ adsorption was accompanied by releasing $\mathrm{H}^{+}$ions into the bulk solution, because the protons in $-\mathrm{C} \pi-\mathrm{H}_{3} \mathrm{O}^{+}$could be exchanged by $\mathrm{Ni}(\mathrm{II})$ cations via proton exchange. In addition, the $\mathrm{H}$ atom in acidic groups (carboxylic and phenolic groups) could also be replaced by metal ions. Hence, these two reactions produced $\mathrm{H}^{+}$ions and reduced the solution $\mathrm{pH}$. The mechanisms of ion exchange for $\mathrm{Ni}(\mathrm{II})$ adsorption are described schematically as follows:

$$
\begin{gathered}
\mathrm{C} \pi \mathrm{H}_{3} \mathrm{O}^{+}+\mathrm{Ni}^{2+} / \mathrm{C} \pi \mathrm{Ni}^{2+}+\mathrm{H}^{+} \\
\mathrm{S}-\mathrm{CO}-\mathrm{H}+\mathrm{Ni}^{2+} / \mathrm{S}-\mathrm{CO}-\mathrm{Ni}^{+}+\mathrm{H}^{+} \\
2(\mathrm{~S}-\mathrm{CO}-\mathrm{H})+\mathrm{Ni}^{2+} / \mathrm{S}-(\mathrm{CO})_{2}-\mathrm{Ni}+2 \mathrm{H}^{+}
\end{gathered}
$$

where $\mathrm{S}$ is the carbon surface, and $\mathrm{COH}$ presents the phenolic hydroxyl or carboxyl.

\subsection{Effect of ionic strength}

The effect of ionic strength $(\mathrm{NaCl})$ on $\mathrm{Ni}(\mathrm{II})$ adsorption was studied. Fig. 5a shows that distribution coefficient $\left(\mathrm{K}_{\mathrm{d}}=\left(\mathrm{C}_{0}-\mathrm{C}_{\mathrm{e}}\right) \mathrm{V} /\left(\mathrm{C}_{\mathrm{e}} \mathrm{M}\right), \mathrm{L} \mathrm{g}^{-1}\right)$ decreased considerably with increase in ionic strength. It suggested that due to high sensitivity to ionic strength variations, ${ }^{43} \mathrm{Ni}$ (II) cations were adsorbed on carbon by ionic interactions corresponding to cation exchange, electrostatic attraction, and outersphere surface complexation. ${ }^{44,45}$ The reduction in $\mathrm{Ni}(\mathrm{II})$ adsorption onto AC-CHs was more obvious than that onto AC-PA. For example, when $\mathrm{NaCl}$ concentration varied from 0 to $0.5 \mathrm{~mol} \mathrm{~L}_{-1}^{-1}$, the $\mathrm{K}_{\mathrm{d}}$ for AC-Glu and AC-PA was reduced from 7.4 to $1.8 \mathrm{~L} \mathrm{~g}^{-1}$ and 2.1 to $0.67 \mathrm{~L} \mathrm{~g}^{-1}$, respectively. This difference was attributed to their larger contents of functional groups, which further confirmed that surface chemistry of activated carbon was mainly responsible for $\mathrm{Ni}(\mathrm{II})$ adsorption. 
Fig. 5b illustrates that final $\mathrm{pH}$ of the samples was independent on solution ionic strength, which suggested that the sites of proton exchange were exhausted after adsorption at different ionic strength. Thus, the Ni(II) adsorption suppression caused by increase of ionic strength was owing to the direct competition of $\mathrm{Na}^{+}$. The high concentration of $\mathrm{Na}^{+}$neutralized the negative surface charge of the carbon and reduced the activity coefficient of $\mathrm{Ni}$ (II), thereby limiting $\mathrm{Ni}$ (II) transfer from solution to the carbon surface and further reducing adsorption of $\mathrm{Ni}(\mathrm{II})$.
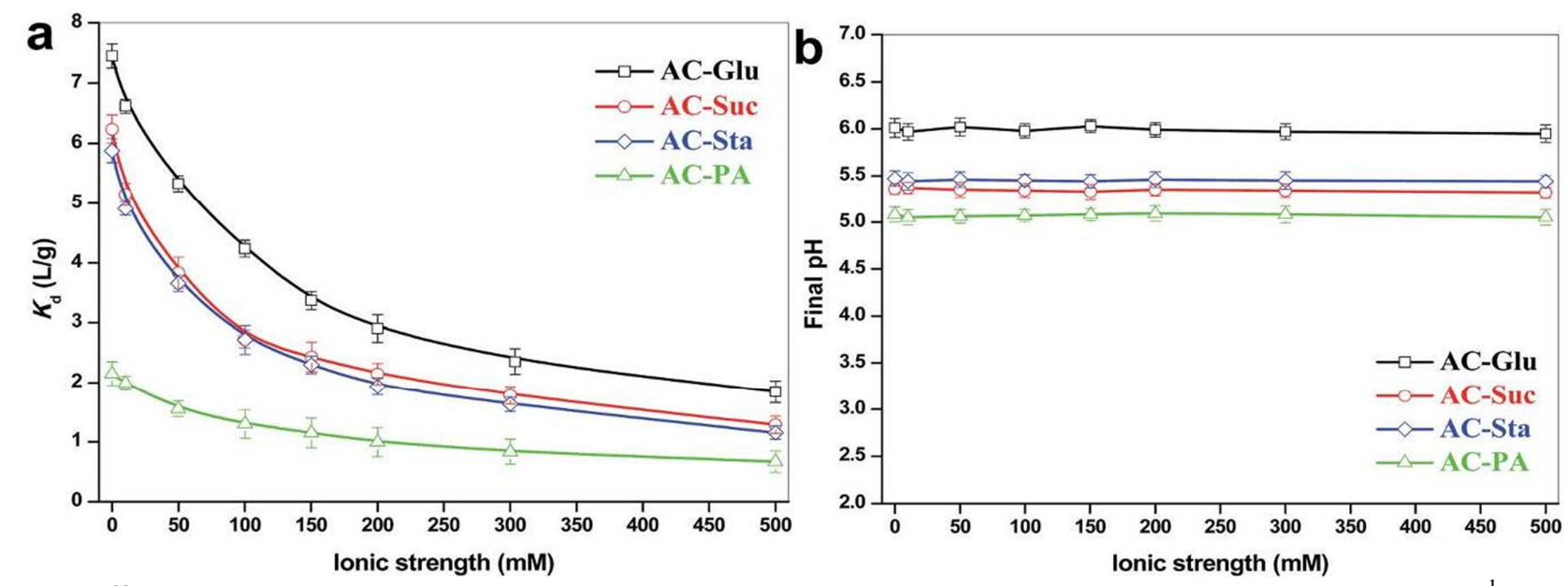

Fig.5 Effect of ionic strength $(\mathrm{NaCl})$ on nickel adsorption (a) by the carbons and solution $\mathrm{pH}$ (b) (dosage $=0.6 \mathrm{gL}^{-1}$, temperature $=25 \pm 2^{\circ} \mathrm{C}$, initial $\mathrm{pH} 6.30 \pm 2$, time $=24 \mathrm{~h}$ ).

\subsection{XPS analysis}

In the Sections 3.4 and 3.5, it has been proposed that $\mathrm{Ni}$ (II) adsorption was accompanied by proton release, which was recognized as ion exchange mechanisms. Besides, surface complexes formation was also observed by adsorption experiments and XPS analyses. ${ }^{46}$ The $-\mathrm{C} \pi$ electrons and oxygen atoms with a pair of free electron in ketone, lactone or ether groups could be involved in the Ni(II) ions adsorption via noncovalent electron donor-acceptor interactions. To further determine the role of surface groups in $\mathrm{Ni}$ (II) adsorption, the surface binding states of AC-Sta and $\mathrm{Ni}$ (II)-adsorbed ACSta (AC-Sta-Ni) were analyzed. The XPS survey spectra together with fitted C $1 \mathrm{~s}, \mathrm{O} 1 \mathrm{~s}$ and Ni $2 \mathrm{p}$ spectra are presented in Fig. 6. The Ni 2p peak was observed from the XPS survey spectrum of AC$\mathrm{Sta}-\mathrm{Ni}$, confirming the presence of metal complexes on carbon surface (Fig. 6a). The peaks at 856 $\mathrm{eV}$ and $861 \mathrm{eV}$ (Ni 2p3/2, Fig. 6b) indicated the bonding between $\mathrm{Ni}(\mathrm{II})$ ions and oxygen functional groups (such as $-\mathrm{C}-\mathrm{O},-\mathrm{COO}, \mathrm{C}-\mathrm{O}-\mathrm{C}$ ).

The deconvolution of the C 1s spectrum for AC-Sta was considered in the forms of graphitized carbon at $284.6 \mathrm{eV}$, phenol, alcohol and ether at $286.2 \mathrm{eV}$, carbonyl at $287.3 \mathrm{eV}$, carboxylic or ester groups at $288.7 \mathrm{eV}$, and $\pi-\pi^{*}$ transitions at $290.5 \mathrm{eV}{ }^{38,49}$ Significant changes were observed in the C $1 \mathrm{~s}$ spectra before and after $\mathrm{Ni}(\mathrm{II})$ adsorption. A part of the peak for $\mathrm{C}=\mathrm{C}$ of graphitized carbon was reduced, and the peak for $\pi-\pi^{*}$ transitions was disappeared after adsorption (Fig. $6 \mathrm{c}$ and $\mathrm{d}$ ). The results revealed that coordination was established with $\mathrm{Ni}^{2+}$ ions and $\pi$ electrons of the carbon.

In addition, XPS survey spectra showed that after $\mathrm{Ni}$ (II) adsorption, the O/C\% of AC-Sta decreased from $145 \%$ to $133 \%$, which suggested the involvement of oxygen-containing functional groups in $\mathrm{Ni}$ (II) adsorption. The $\mathrm{O} 1 \mathrm{~s}$ spectrum of AC-Sta was resolved into three components corresponding to: (I) $\mathrm{C}=\mathrm{O}$ groups (carbonyl groups) at $531.2 \mathrm{eV}$, (II) $\mathrm{C}-\mathrm{OH}$ or $\mathrm{C}-\mathrm{O}-\mathrm{C}$ groups (hydroxyl or ether) at $532.4 \mathrm{eV}$, and (III) $\mathrm{O}=\mathrm{C}-\mathrm{O}$ groups (anhydride, lactone, or carboxylic acids) at $533.4 \mathrm{eV}{ }^{39}$ Furthermore, it can be observed in Fig. 6e and $\mathrm{f}$ that the three differentiated peaks shifted apparently to 
higher binding energy sides after metal adsorption, reflecting that $\mathrm{O}$ atoms in these groups donated a lone pair of electrons to form complexes with $\mathrm{Ni}(\mathrm{II})$ ions. Similarly, the trend coincided with the slight shifts of peaks 2, 3 and 4 for $\mathrm{C} 1 \mathrm{~s}$ after $\mathrm{Ni}$ (II) adsorption (Fig. 6d).

a

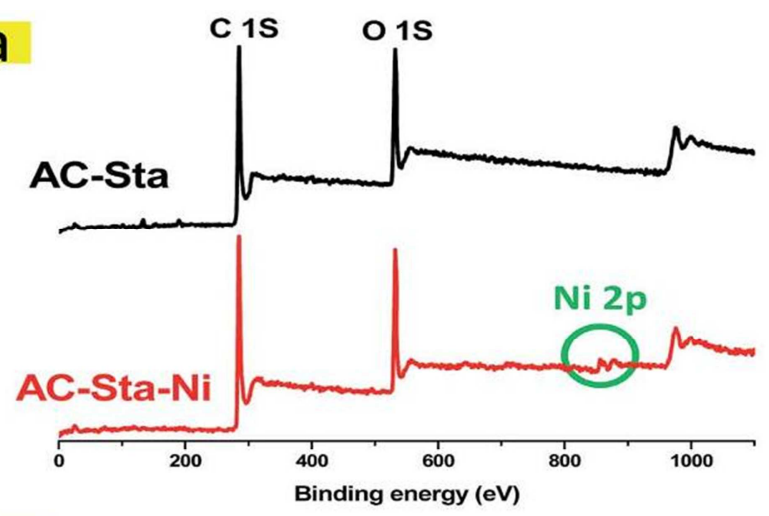

C AC-Sta

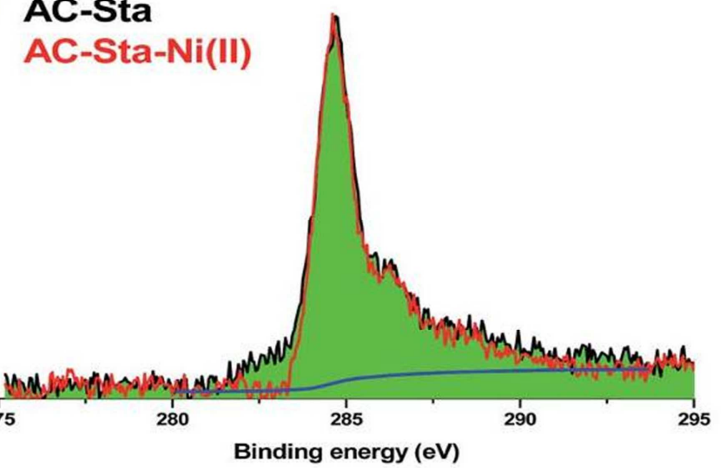

e

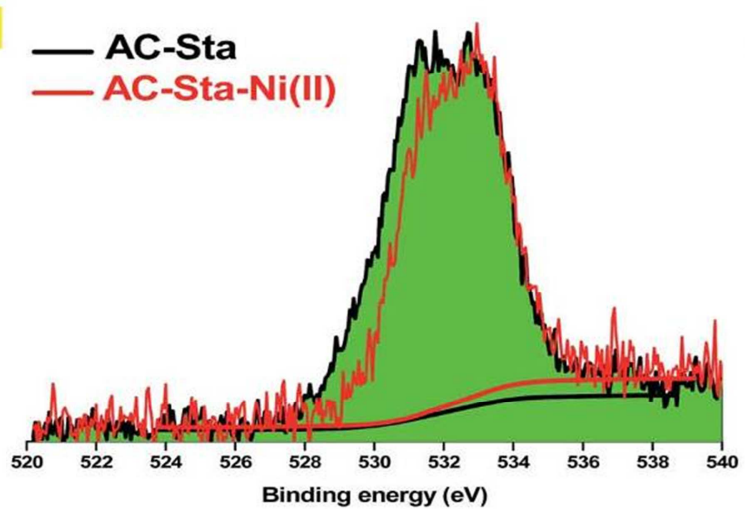

b

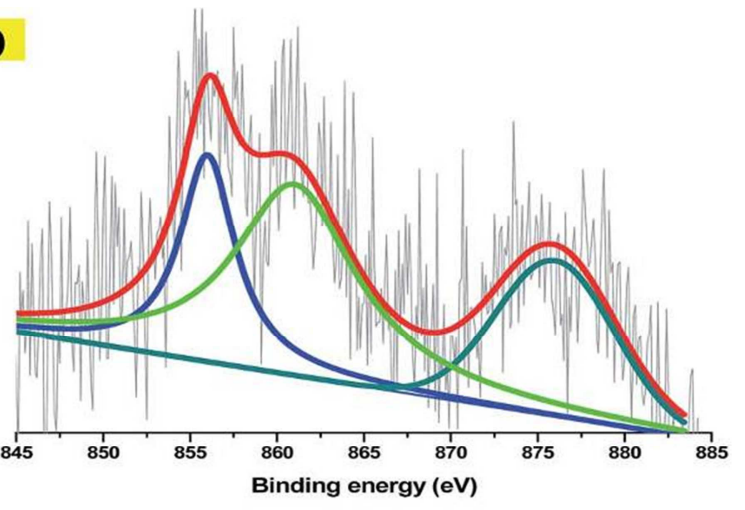

d

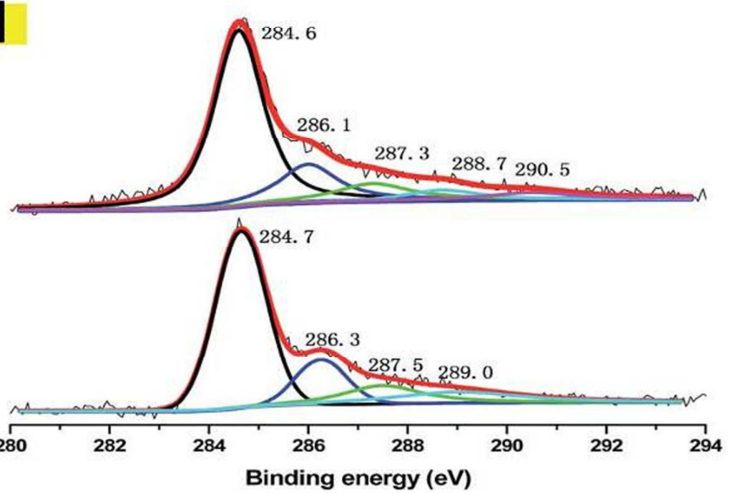

f

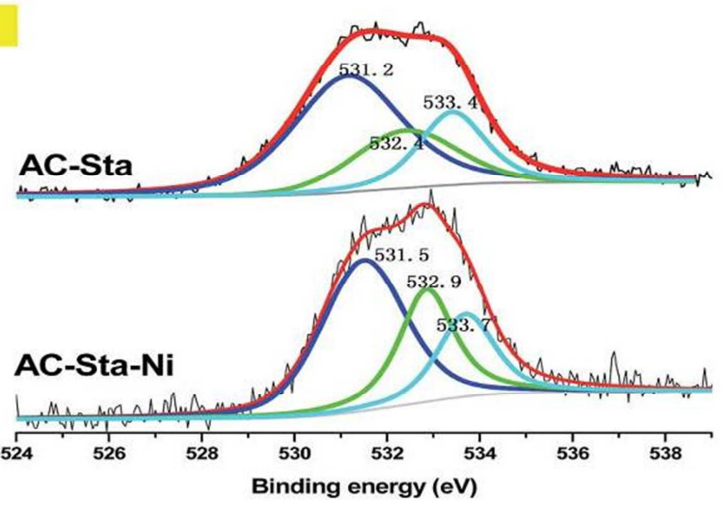

Fig.6 XPS spectra for AC-Sta before and after nickel uptake: survey spectra (a), Ni2p3/2 (b), C 1s (c) and (d), and O 1s (e) and(f).

\subsection{Adsorption kinetics studies}

Since adsorption is a surface phenomenon, adsorption rate is influenced by both pore characteristics and surface chemical properties of the adsorbents. Thus, in order to further evaluate the main factor that controlled the $\mathrm{Ni}(\mathrm{II})$ adsorption rate, the effect of contact time on metal ion uptake in terms of determining $\mathrm{Ni}(\mathrm{II})$ adsorption equilibrium time were performed. It can be observed from Fig. 7 that the adsorption increased rapidly in the first $30 \mathrm{~min}$, and then continued to rise gradually and got equilibrium within $3 \mathrm{~h}$ for all samples. Equilibrium adsorption capacity of $\mathrm{Ni}(\mathrm{II}), \mathrm{Q}_{\mathrm{e}}\left(\mathrm{mg} \mathrm{g}^{-1}\right.$ ), increased as the increment of initial concentration due to the increased driving force caused by $\mathrm{Ni}(\mathrm{II})$ concentration gradient. $\mathrm{Ni}(\mathrm{II})$ adsorption rates and ability of $\mathrm{AC}-\mathrm{CH}$ s were significantly higher than those of AC-PA at the three initial $\mathrm{Ni}$ (II) concentrations, reflecting a better $\mathrm{Ni}(\mathrm{II})$ adsorption performance. It is worthy to note that $95 \%$ of maximum adsorption capacity was achieved within 30 
min for all samples, indicating that the AC-CHs could be desirable adsorbents for wastewater treatment plant applications.
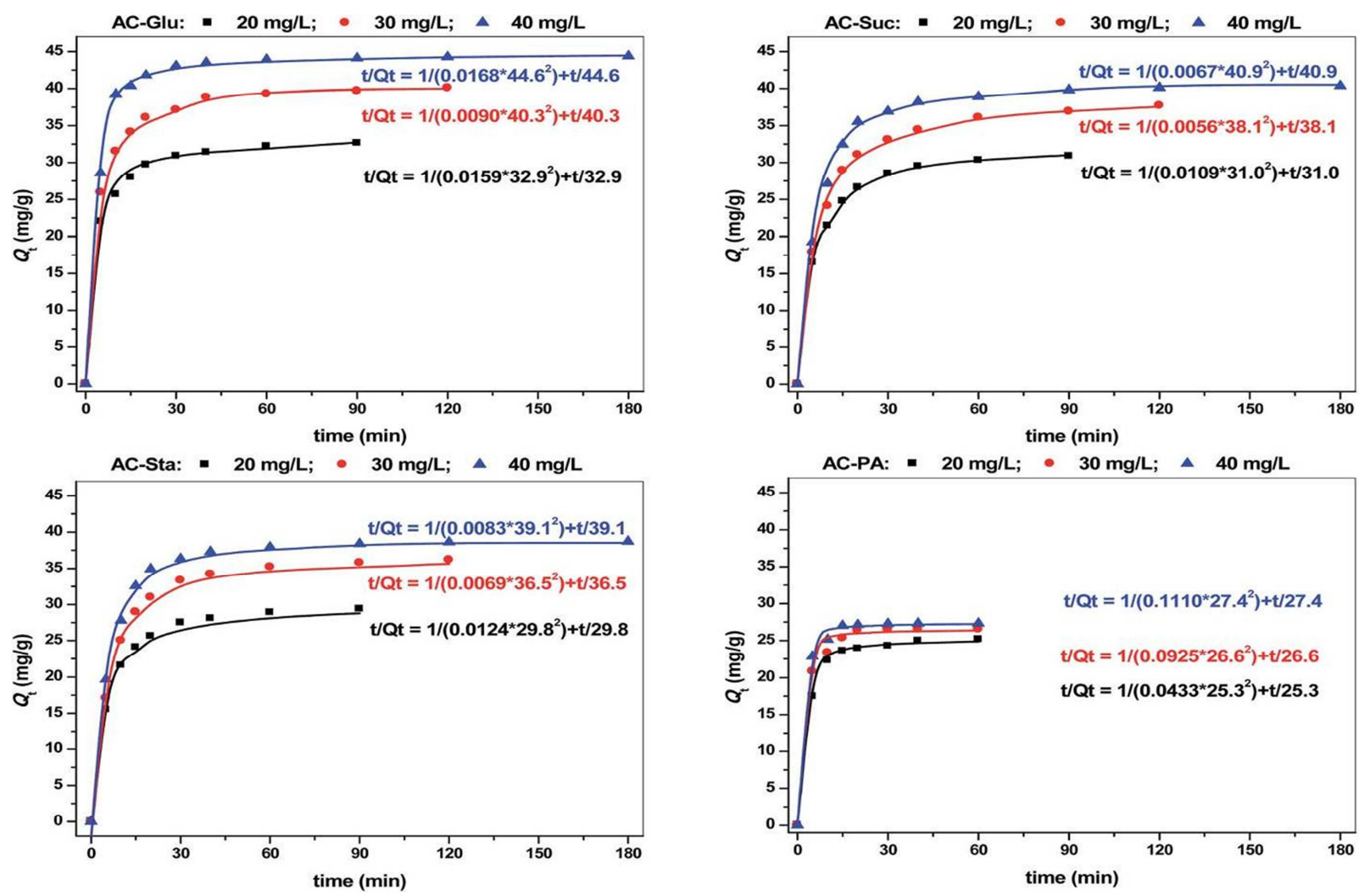

Fig.7 Adsorption kinetics of nickel on AC-Glu(a), AC-Suc(b), AC-Sta(c) and AC-PA(d) at three initial concentrations. Lines represent the adsorption data fitted with the pseudo-second order mode (dosage $=0.6 \mathrm{gL}^{-1}$, temperature $=25 \pm 2^{\circ} \mathrm{C}$, initial pH $6.00 \pm 2$ ).

Fig. 7 shows the simulation of $\mathrm{Ni}($ II) adsorption data using nonlinear pseudo-second order model. Obviously, pseudo-second order model fitted the experimental data very well (Fig. 7). The good fit $\left(\mathrm{R}^{2}>0.999\right)$ indicated a predominant chemisorption rate-controlling mechanism, which also could be demonstrated based on the similar equilibrium time for $\mathrm{Ni}(\mathrm{II})$ adsorption on AC-Glu, AC-Suc and $\mathrm{AC}$-Sta and their longer equilibrium time in comparison with that on AC-PA. As $\mathrm{S}_{\mathrm{BET}}$ and $\mathrm{V}_{\text {mic }}$ of AC-Sta were very small and could be negligible when comparing with the other three carbon (Table 1), intraparticle diffusion for $\mathrm{Ni}(\mathrm{II})$ adsorption was very limited. Accordingly, this phenomenon suggested that the internal and external surfaces of the porous carbon were easily accessible for $\mathrm{Ni}(\mathrm{II})$ ions. Regarding AC-CHs, AC-Glu had the quickest initial adsorption, as it had the highest contact area and the most probable adsorption sites. For the four carbon samples, AC-PA represented the shortest equilibrium time and lowest adsorption capacity as it contained the least probable adsorption sites (acidic and basic groups).

\section{Conclusion}

This study demonstrated that the three carbohydrates, glucose, sucrose and starch, can be used as promising carbon precursors for developing activated carbon with favorable physicochemical characteristics and high $\mathrm{Ni}(\mathrm{II})$ adsorption capacity by phosphoric acid activation. The results of physical and chemical analyses indicated that the carbohydrates-based activated carbon (AC-CHs) exhibited less surface area but higher surface acidity and basicity than activated carbon derived from 
conventional lignocellulose material (Phragmites australis). The Ni(II) adsorption capacity of ACCHs was notably higher than that of AC-PA, which was mainly attributed to their larger contents of both acidic and basic groups. As revealed by the batch Ni(II) adsorption experiments and XPS analysis, the proton exchange, electrostatic interaction, and complexation between $\mathrm{Ni}$ (II) cations and delocalized $\pi$ electrons of graphene surface/oxygenated acidic functionalities were mainly responsible for $\mathrm{Ni}$ (II) adsorption on activated carbon. The adsorption rate of $\mathrm{Ni}$ (II) was controlled by interactions between $\mathrm{Ni}$ (II) ions and functional groups of the carbon. There results confirmed that the $\mathrm{Ni}$ (II) adsorption capacity and rate were controlled by the surface chemistry of activated carbon. To date, no relevant research has been reported, so that more research for choosing suitable activation parameters is necessary for using as an alternative to the traditional carbon precursors as well as developing of effective adsorbents to treat $\mathrm{Ni}$ contaminated water.

\section{Acknowledgements}

This work was supported by the Independent Innovation Foundation of Shandong University (2012JC029), Natural Science Foundation for Distinguished Young Scholars of Shandong province (JQ201216) and National Water Special Project (2012ZX07203-004). The authors gratefully acknowledge the fund from Shanghai Tongji Gao Tingyao Environmental Science and Technology Development Foundation.

\section{References}

1 T. L. Wade, S. T. Sweet and A. G. Klein, Environ. Pollut., 2008, 152, 505-521.

2 L. Kanhai, J. Gobin, D. Beckles, B. Lauckner and A. Mohammed, Environ. Monit. Assess., 2014, 186, 1961-1976.

3 S. A. Ahmed, M. A. Qadir, M. N. Zafar, I. Hussain, S. Tufail, S. Rashid and H. A. Shah, J. Hazard. Mater., 2008, 157, 564-568.

4 S. Yang, J. Li, D. Shao, J. Hu and X. Wang, J. Hazard. Mater., 2009, 166, 109-116.

5 M. J. Eckelman, Resour., Conserv. Recycl., 2010, 54, 256-266.

6 G. E. Millward, S. Kadam and A. N. Jha, Environ. Pollut., 2012, 162, 406-412.

7 D. Hoffman, Bull. Environ. Contam. Toxicol., 1979, 23, 203- 206.

8 Y. Wu, H. Luo, H. Wang, L. Zhang, P. Liu and L. Feng, J. Colloid Interface Sci., 2014, 436,90-98.

9 L. Fang, W. Li, H. Chen, F. Xiao, L. Huang, P. E. Holm, H. C. B. Hansen and D. Wang, RSC Adv., 2015, 5, 18866- 18874 .

10 K.-H. Kim, Z.-H. Shon, P. T. Mauulida and S.-K. Song, Chemosphere, 2014, 111, 312-319.

11 M. Machida, B. Fotoohi, Y. Amamo, T. Ohba, H. Kanoh and L. Mercier, J. Hazard. Mater., 2012, 221-222, 220-227.

12 X. Song, P. Gunawan, R. Jiang, S. S. J. Leong, K. Wang and R. Xu, J. Hazard. Mater., 2011, 194, 
$162-168$.

13 R. Madhu, K. V. Sankar, S.-M. Chen and R. K. Selvan, RSC Adv., 2014, 4, 1225-1233.

14 S. Vasudevan and J. Lakshmi, RSC Adv., 2012, 2, 5234-5242.

15 H. L. Parker, A. J. Hunt, V. L. Budarin, P. S. Shuttleworth, K. L. Miller and J. H. Clark, RSC Adv., 2012, 2, 8992-8997.

16 E. R. Nightingale, J. Phys. Chem., 1959, 63, 1381-1387.

17 R. Berenguer, J. P. Marco-Lozar, C. Quijada, D. Cazorla Amoros and E. Morallon, Carbon, 2012, 50, 1123-1134.os and E. Morall'

18 H. Liu, P. Dai, J. Zhang, C. Zhang, N. Bao, C. Cheng and L. Ren, Chem. Eng. J., 2013, 228, 425434.

19 J. Jaramillo, V. Gomez-Serrano and P.M Alvarez, J. Hazard. omez-Serrano and P. M. 'Mater., 2009, 161, 670-676.

20 X. Cao, L. Ma, B. Gao and W. Harris, Environ. Sci. Technol., 2009, 43, 3285-3291.

21 W. Liu, J. Zhang, C. Cheng, G. Tian and C. Zhang, Chem. Eng. J., 2011, 175,24-32.

22 A. A. Ismaiel, M. K. Aroua and R. Yusoff, Chem. Eng. J., 2013, 225, 306-314.

23 X. Q. Wang, P. Wang, P. Ning, Y. X. Ma, F. Wang, X. L. Guo and Y. Lan, RSC Adv., 2015, 5, 24899-24907.

24 Z. Zhou, Z. Zhang, H. Peng, Y. Qin, G. Li and K. Chen, RSC Adv., 2014, 4, 5524-5530.

25 H. Guedidi, L. Reinert, J.-M. L’ev^eque, Y. Soneda, N. Bellakhal and L. Duclaux, Carbon, 2013, $54,432-443$.

26 S. X. Liu, X. Chen, X. Y. Chen, Z. F. Liu and H. L. Wang, J. Hazard. Mater., 2007, 141, 315-319.

27 A. H. El-Sheikh, Talanta, 2008, 75, 127-134.

28 J. Jaramillo, P. M. Alvarez and V. G'Fuel 'omez-Serrano, Process. Technol., 2010, 91, 17681775.

29 M. Sevilla and A. B. Fuertes, Chem.-Eur. J., 2009, 15, 4195- 4203.

30 M. Sevilla, J. A. Macia-Agullo and A. B. Fuertes, Biomass Bioenergy, 2011, 35, 3152-3159.

31 H. Liu, J. Zhang, C. Zhang, N. Bao and C. Cheng, Carbon, 2013, 60, 289-291.

32 H. Liu, X. Wang, G. Zhai, J. Zhang, C. Zhang, N. Bao and C. Cheng, Chem. Eng. J., 2012, 209, $155-162$.

33 H. P. Boehm, Carbon, 2002, 40, 145-149.

34 J. J. M. Orfao, A. I. M. Silva, J. C. V. Pereira, S. A. Barata, I. M. Fonseca, P. C. C. Faria and M. F. R. Pereira, J. Colloid Interface Sci., 2006, 296, 480-489.

35 J. Wang, H. Liu, S. Yang, J. Zhang, C. Zhang and H. Wu, Appl. Surf. Sci., 2014, 316, 443-450. 
36 K. Laszlo, Microporous Mesoporous Mater., 2005, 80, 205-211.

37 J. A. Menendez, B. Xia, J. Phillips and L. R. Radovic, Langmuir, 1997, 13, 3414-3421.

38 G.-X. Yang and H. Jiang, Water Res., 2014, 48, 396-405.

39 X. Dong, L. Q. Ma, Y. Zhu, Y. Li and B. Gu, Environ. Sci. Technol., 2013, 47, 12156-12164.

40 S. Yang, J. Li, Y. Lu, Y. Chen and X. Wang, Appl. Radiat. Isot., 2009, 67, 1600-1608.

41 G. P. Rao, C. Lu and F. Su, Sep. Purif. Technol., 2007, 58, 224-231.

42 J. Rivera-Utrilla and M. Sanchez-Polo, Water Res., 2003, 37, 3335-3340.

43 C. Chen and X. Wang, Appl. Radiat. Isot., 2007, 65, 155-163.

44 M.-q. Jiang, Q.-p. Wang, X.-y. Jin and Z.-1. Chen, J. Hazard. Mater., 2009, 170, 332-339.

45 A. A. El-Bayaa, N. A. Badawy and E. A. AlKhalik, J. Hazard. Mater., 2009, 170, 1204-1209.

46 J.-W. Shim, S.-J. Park and S.-K. Ryu, Carbon, 2001, 39, 1635- 1642.

47 X. Tan, M. Fang, C. Chen, S. Yu and X. Wang, Carbon, 2008, 46, 1741-1750.

48 P. X. Sheng, Y.-P. Ting, J. P. Chen and L. Hong, J. Colloid Interface Sci., 2004, 275, 131-141.

49 A. Swiatkowski, M. Pakula, S. Biniak and M. Walczyk, Carbon, 2004, 42, 3057-3069. 